\title{
Evaluation to Reduce Occupational Risk In Excavator Manufacturing
}

\author{
Euis Nina Saparina Yuliani ${ }^{1}$, Galih Prakoso ${ }^{2}$, Hardianto Iridiastadi ${ }^{3}$, I Putu Gede Adiatmika ${ }^{4}$
}

\author{
Ergonomics and Work Physiology Program-Udayana University \\ Jimbaran \\ ensy08@yahoo.com \\ Industrial Engineering Program-Mercu Buana University \\ Jakarta \\ Industrial Engineering Program-Institut Teknologi Bandung \\ Bandung \\ Ergonomics and Work Physiology Program-Udayana University \\ Jimbaran
}

\begin{abstract}
Musculoskeletal disorders often occur in non-ergonomic work postures. The research was conducted in the process of installing an air cleaner workstation for the excavator's assembly at a heavy equipment manufacturing company. In the installation process, the operator must lift, hold and install the component with weight $12 \mathrm{~kg}$, using the limbs manually without any tools. The objective of this study is to conduct an ergonomic evaluation by assessing the risk of musculoskeletal disorders and provide recommendations for improvement in order to reduce operator musculoskeletal injuries. To determine the level of risk of the job will be used the Rapid Entire Body Assessment method. The results of this study are R.E.B.A scores obtained which is 11, with a very high level of risk, and must be immediately corrected. Ergonomic intervention as a recommendation for improvements that support the work of the operator, is making jigs to help the installation process. After implementation, the REBA score dropped to 3 or decreases by around $67 \%$ from the initial risk
\end{abstract}

Index Terms - ergonomics intervention, musculoskeletal disorders, rapid entire body assessment

\section{INTRODUCTION}

The manufacturing industry in Indonesia still involves a lot of operator physical activity. Assembling work is often done manually by operators using limbs. This research was conducted at a heavy equipment manufacturer. The company produces medium excavators with 10 tons, 20 tons and 30 tons in weight. The factory has three main production processes that are done to make the final product of the excavator there are welding or fabrication process, then assembling process and finally painting process.

The welding process in this company has used a lot of welding robots so that the operator only needs to put the components on the robotic welding machine table then welding robots automatically do the welding work. The painting process is carried out using a conveyor and continuously enters into the Electro Deposit Painting room which automatically coating the components with the paint. The operator's involvement in this line is also very small, only just monitoring the painting process in the chamber and checking the quality of the paint thickness.

The chosen production line is line assembling where the manual installation process is still carried out by many operators. One of the installation processes without tools help such as cranes in this company is air cleaner installation. Therefor the operator is required to lift, hold and install the component $12 \mathrm{~kg}$ in weight using the limbs manually without any tools.

Based on the description that has been explained above, it is necessary to conduct an assessment of the operator's postural bodywork in the process of air cleaner assembly. 
Then the objective of this study is to conduct an ergonomic evaluation by assessing the risk of musculoskeletal disorders and provide recommendations for improvement to reduce the operator's musculoskeletal disorder.

Ergonomics is the study of human abilities and characteristics which affect the design of equipment, systems and job [1]. Musculoskeletal disorders (MSDs) are injuries or pain in the human musculoskeletal system, including the joints, ligaments, muscles, nerves, tendons, and structures that support limbs, neck and back [2]. To determine the level of risk of the job will be used the Rapid Entire Body Assessment (R.E.B.A) method.

Rapid Entire Body Assessment is a method developed in the ergonomic field and can be used to assess the work posture of the operator's neck, back, arms, wrists and feet quickly. In addition, this method is also influenced by coupling factors, external loads supported by the body and worker activities [3]. Assessment using REBA does not require a long time to complete and do a general scoring on the list of activities that indicate the need for risk reduction caused by the operator's work posture [3].

\section{METHOD AND PROCEDURES}

This research is based on an exploratory design where systematic steps are carried out in stages to find out how to assess work postures and take corrective actions for the work posture. The steps for assessing the R.E.B.A method are as shown in Figure 1 [3].

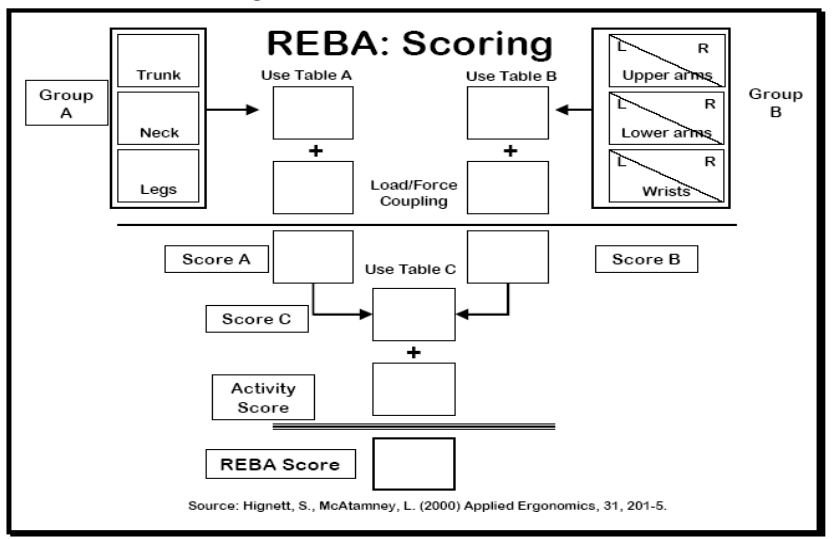

Fig. 1. Steps for REBA Method Calculation (source: Yuliani)

Step 1 Record body posture movements. The body is divided into 2 segments or group, group A and B. Group A includes the upper and lower arms, and wrists. While group B covers the neck, back, and legs. This is to ensure that all postures are recorded so that any awkwardness or limitation of posture by the legs, back or neck that might affect the upper limb posture can be included in the assessment.

Step 2 Determine the angles of the posture. Broadly speaking, limbs are divided into two parts or groups. Group A consists of the neck, back, and legs. Then group B for the upper arm, forearm, and wrist.

Step 3 Determine the weight of the load and activity. A single score is needed from Groups A and B which can represent the level of posture loading of the musculoskeletal system in relation to the combination of body part postures. The sum of the load score with the score of table A produces a score of $\mathrm{A}$. While the sum of the coupling score with the posture score of table B produces a score B. Then the score A and score B are used to read table $\mathrm{C}$ which finally gets the score C. Finally the $\mathrm{C}$ score is summed up with the activity score the final score is the R.E.B.A value.

Step 4 Calculate the score for each angle, load, and activity. This stage aims to combine the $\mathrm{C}$ score and the activity score into a single grand score that can provide guidance on the priority of subsequent investigations. Each possible combination of $\mathrm{C}$ scores and activity scores has been given a rating, called the grand score from 1 to $11+$ based on estimated risk of injury associated with musculoskeletal loading.

Step 5 Determine the Level action. Based on the grand score of the $\mathrm{C}$ score and activity score, the actions to be taken can be divided into 5 action levels.

Action Level 1: A score of 1 indicates that the posture can be accepted as long as it is not maintained or repeats for a long time. Action Level 2: Scores 2 to 3 indicate that further investigation is needed and that changes may be needed. Action Level 3: Scores 4 to 7 indicates that investigations and changes are needed immediately. Action Level 4: Scores 8 to 10 indicate that investigations and changes are needed as soon as possible (urgent). Action Level 5: Score 11 indicates that implementation and changes are needed right now.

REBA method can be used to determine the risk level of each work station on the production line and classify work stations from very high risk to non-risk work stations based on the REBA score obtained [4]. The percentage of risk of each movement can also be determined after REBA calculation [5]. Critical variables of a body's work posture can also be known using the REBA method. Critical variables are the variables that have the greatest influence on the final REBA score [6].

Using high-level computer graphics simulations and other engineering equipment simulations, which finally concluded 2D and 3D simulation devices with ergonomic analysis functions proved to be very powerful tools for designing manufacturing and ergonomic systems [7]. AutoCAD software able to measure angle of postural body. Then based on measurement result, step by step of R.E.B.A can be done.

\section{RESULT}

The work body position carried out by operators in the air cleaner assembly line on work activities can be seen in Table 1 showing work postures when carrying out activities. 
Table 1. An Air Cleaner Component Movement Installation

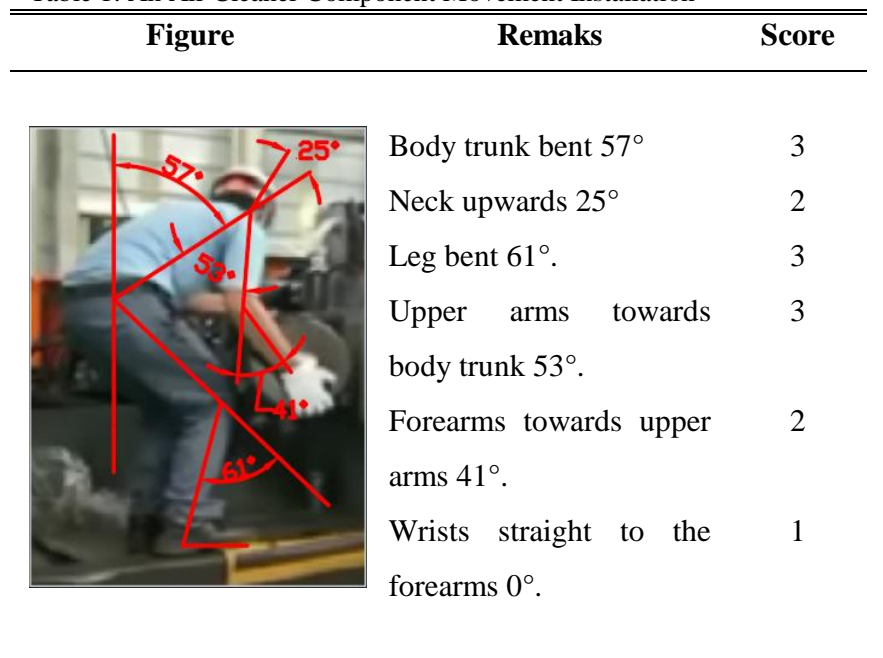

Standing work posture has several conditions related to Work Related Musculoskeletal Disorders (WMSDs). Low back pain is one of the problems in standing work posture with the back position leaning forward. Working posture for too long will cause a buildup of blood in the vein, because blood flow is opposite to gravity. This condition can cause ankle swelling [8].

As a benchmark, the zero lines is a straight line when standing upright. Furthermore, the line is drawn from the zero lines to the position of the torso or operator's back. Then the neckline is pulled back against the torso. After that, arm lines are drawn against the torso, then the upper legs, namely thighs to knees to the torso. Finally, draw the lower leg line towards the upper leg.

Measuring results using AutoCAD form certain angles which will then be the basis for calculating R.E.B.A scores. The score obtained from the position of the operator's posture will be accumulated with the load score and coupling so that the final score is obtained indicating the level of work risk of the operator.

The score results from the operator's work posture at the work station for the installation of an air cleaner are shown in Table 2.

Table 2. Calculation Grup A, B And C

\begin{tabular}{|c|c|c|c|c|c|c|c|c|c|c|c|c|c|}
\hline \multirow{2}{*}{$\begin{array}{c}\text { Table } \\
\text { A }\end{array}$} & \multicolumn{13}{|c|}{ Neck } \\
\hline & & \multicolumn{4}{|c|}{1} & \multicolumn{4}{|c|}{ (2) } & \multicolumn{4}{|c|}{3} \\
\hline & \multirow{2}{*}{ Legs } & & & & & & & & & & & & \\
\hline & & 1 & 2 & 3 & 4 & 1 & 2 & (3) & 4 & 1 & 2 & 3 & 4 \\
\hline \multirow{5}{*}{$\begin{array}{c}\text { Trunk } \\
\text { Posture } \\
\text { Score }\end{array}$} & 1 & 1 & 2 & 3 & 4 & 1 & 2 & 1 & 5 & 3 & 3 & 5 & 6 \\
\hline & 2 & 2 & 3 & 4 & 5 & 3 & 4 & 1 & 6 & 4 & 5 & 6 & 7 \\
\hline & (3) & t & 7 & 7 & $v$ & 4 & $t$ & 6 & 7 & 5 & 6 & 7 & 8 \\
\hline & 4 & 3 & 5 & 6 & 7 & 5 & 6 & 7 & 8 & 6 & 7 & 8 & 9 \\
\hline & 5 & 4 & 6 & 7 & 8 & 6 & 7 & 8 & 9 & 7 & 8 & 9 & 9 \\
\hline
\end{tabular}

\begin{tabular}{|c|c|c|c|c|c|c|c|}
\hline \multirow{2}{*}{$\begin{array}{c}\text { Table } \\
\text { B }\end{array}$} & \multicolumn{7}{|c|}{ Lower Arm } \\
\hline & & \multicolumn{3}{|c|}{1} & \multicolumn{3}{|c|}{ (2) } \\
\hline & \multirow{2}{*}{ Wrist } & & & & & & \\
\hline & & 1 & 2 & 3 & 1 & 2 & 3 \\
\hline \multirow{6}{*}{$\begin{array}{l}\text { Upper } \\
\text { Arm } \\
\text { Score }\end{array}$} & 1 & 1 & 2 & 2 & 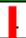 & 2 & 3 \\
\hline & 2 & 1 & 2 & 3 & 3 & 3 & 4 \\
\hline & (3) & 9 & 4 & 5 & 4 & 5 & 5 \\
\hline & 4 & 4 & 5 & 5 & 5 & 6 & 7 \\
\hline & 5 & 6 & 7 & 8 & 7 & 8 & 8 \\
\hline & 6 & 7 & 8 & 8 & 8 & 9 & 9 \\
\hline
\end{tabular}

\begin{tabular}{|c|c|c|c|c|c|c|c|c|c|c|c|c|}
\hline \multirow{2}{*}{$\begin{array}{c}\text { Score A } \\
\text { (score form } \\
\text { table A } \\
\text { +load/force } \\
\text { score) }\end{array}$} & \multicolumn{10}{|c|}{ Table C } \\
\cline { 2 - 14 } & 1 & 2 & 3 & 4 & 5 & 6 & 7 & 8 & 9 & 10 & 11 & 12 \\
\hline 1 & 1 & 1 & 1 & 2 & 1 & 3 & 4 & 5 & 6 & 7 & 7 & 7 \\
\hline 2 & 1 & 2 & 2 & 3 & & 4 & 5 & 6 & 6 & 7 & 7 & 8 \\
\hline 3 & 2 & 3 & 3 & 3 & & 5 & 6 & 7 & 7 & 8 & 8 & 8 \\
\hline 4 & 3 & 4 & 4 & 4 & & 6 & 7 & 8 & 8 & 9 & 9 & 9 \\
\hline 5 & 4 & 4 & 4 & 5 & & 7 & 8 & 8 & 9 & 9 & 9 & 9 \\
\hline 6 & 6 & 6 & 6 & 7 & & 8 & 9 & 9 & 10 & 10 & 10 & 10 \\
\hline 7 & 7 & 7 & 7 & 8 & 7 & 9 & 9 & 10 & 10 & 11 & 11 & 11 \\
\hline 8 & 8 & 8 & 8 & 9 & 10 & 10 & 10 & 10 & 10 & 11 & 11 & 11 \\
\hline 9 & 9 & 9 & 9 & 10 & 10 & 10 & 11 & 11 & 11 & 12 & 12 & 12 \\
\hline 10 & 10 & 10 & 10 & 11 & 11 & 11 & 11 & 12 & 12 & 12 & 12 & 12 \\
\hline 11 & 11 & 11 & 11 & 11 & 11 & 12 & 12 & 12 & 12 & 12 & 12 & 12 \\
\hline 12 & 12 & 12 & 12 & 12 & 12 & 12 & 12 & 12 & 12 & 12 & 12 & 12 \\
\hline
\end{tabular}

R.E.B.A value is obtained from the sum of score $\mathrm{C}$ with the activity score. In carrying out activities, the operator's body position experiences repetition of movements and unstable position so that the activity score is 1. R.E.B.A Score $=$ C Score + activity score $=10+1=11$

Recapitulation of the results of the total assessment can be seen in Figure 2.

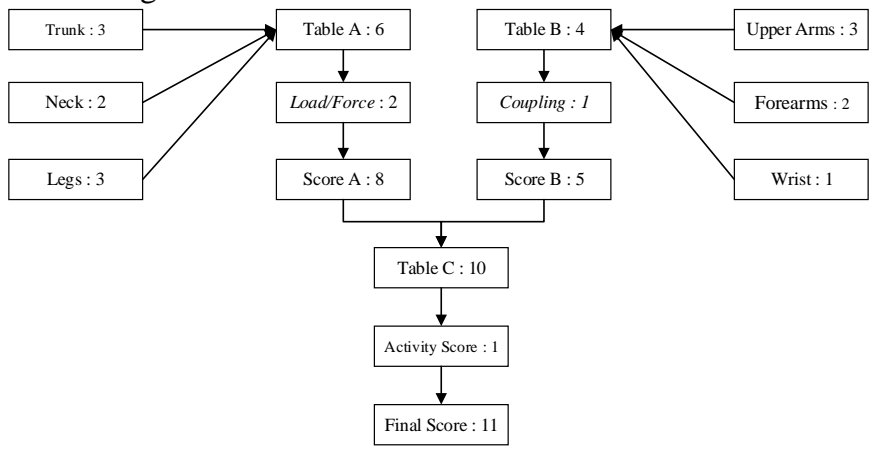

Fig. 2. Chart of Total REBA Score Recapitulation (source: Yuliani)

\section{DISCUSSION}

Based on the calculation of the R.E.B.A score, it can be seen the level of action that is level 5 with a very high level of risk at musculoskeletal, that is, it must be done now necessary to reduce workplace risk.

With the software to model it in a real way, the appropriate tools are designed to improve the work posture. The average height of the operator at the air cleaner assembly station is $166 \mathrm{~cm}$ while the position of the installation of the air cleaner is at $155 \mathrm{~cm}$. The operator needs to climb the stairs and then install the sambal to hold the component weight.

Therefore, so that the operator only focuses on the installation of the components, it does not need to hold back 
using his legs or arms, so that a retaining jig is made so that it accelerates and makes it easier for the operator to work. Figure 3 shows the position of the components to be attached to body posture. The mounting position of the component is around $1500 \mathrm{~mm}$ or $150 \mathrm{~cm}$. while the average operator height is $1660 \mathrm{~mm}$ or $166 \mathrm{~cm}$. it can be seen that the height of the component installation is only $16 \mathrm{~cm}$ difference to body height.

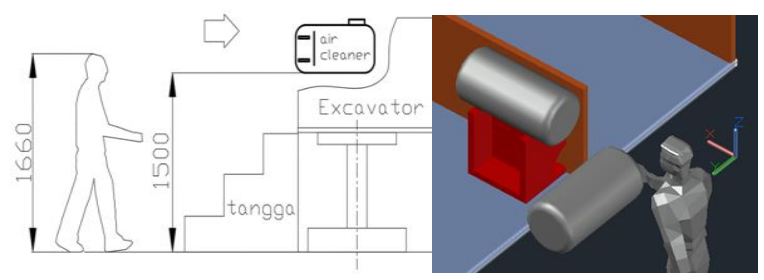

Fig. 3. Work Position Simulation

The mounting position, which is almost as high as the operator's height, makes it difficult to install this air cleaner component. The current condition of the company makes a ladder for the operator to go to the installation site. So the operator carries the component up the stairs and then installs it.

When carrying out the installation, the operator holds the weight of the components on his thighs in a kneeling position. This kind of work posture based on analysis using the methods that have been done turns out to need to improve work posture.

The tool is made a prototype using wood as a temporary material that only functions as a dimensional representation to ensure the exact position of the installation of the air cleaner component. The position of the trial can be seen in Figure 4 and 5.
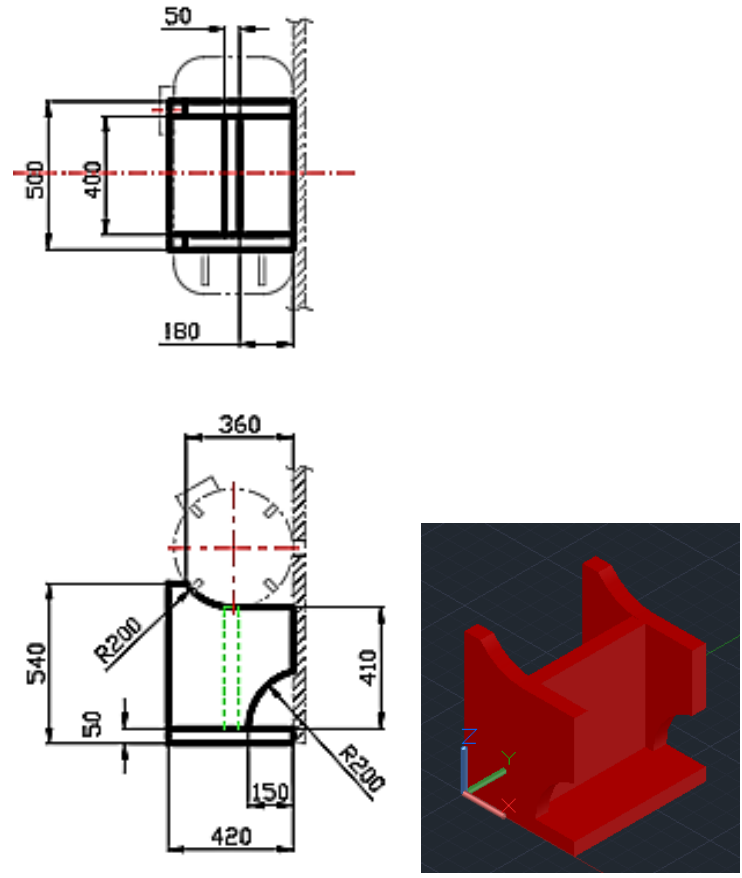

Figure 4. Jig Concept Design

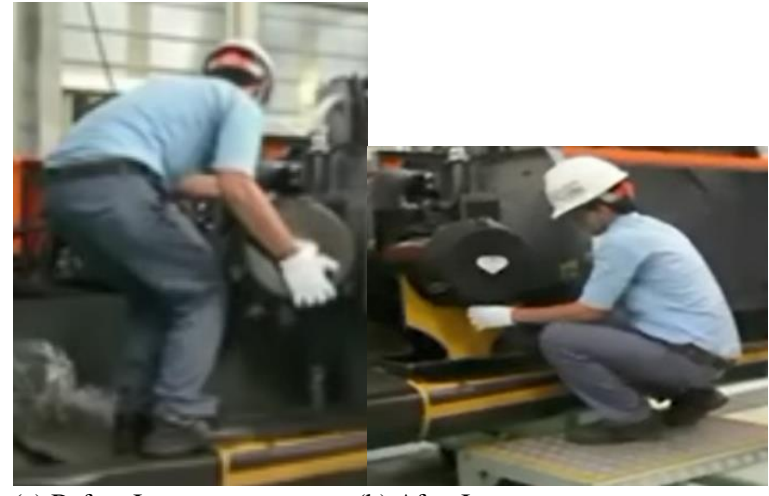

(a) Before Improvement

(b) After Improvement

Fig. 5. Test and Comparison before and after Improvement

Comparison of R.E.B.A scores before and after the use of the jig affects the following points:

1. Leg scores

No part of the leg adjustment anymore is the impact of the load which was initially borne by the leg, then the load repair condition is borne by the jig so the operator's feet do not move to make adjustments. Therefore the original leg score 3 changed to 2 .

2. Upper Arm Score

In the Upper Arm, there is a change in score because the hands are free not to hold the load so they are no longer static and free in any position. Assuming the hand in the normal body position between $0{ }^{\circ}-20^{\circ}$ the score for the upper arm is 1 .

3. Lower Arm Score

Same as the upper arm, position the lower arm because it no longer holds the load so the hand angle becomes in the range of $60^{\circ}-100^{\circ}$ so the R.E.B.A score becomes 1 from the original is 2 .

\section{Load / Force Score}

For the score of the load to be 0 , because the body of both the foot and hand no longer accepts the burden of the component of the air cleaner so the score becomes 0 .

5. Coupling Score

How to handle this installer job becomes easier with the jig, the coupling score decreases to 0 .

The final score of the R.E.B.A score as in the calculation of the previous R.E.B.A score obtained from the $\mathrm{C}$ score is added to the activity score. Activity score with no barrier and only pure component installation, operator position is more stable than before the repair.

Related to the existence of a tool, the activity of the operator becomes 0 because the static position is no longer carried out by the operator, but is replaced by a jig. The last score of total R.E.B.A is the table value $\mathrm{C}=3$ plus the activity value $=0$ so that the total score is $=3$.

The final R.E.B.A estimate score after repairs is 3. As seen in Tabel 3 and Figure 6 and the risk level is shown in the chart that the final R.E.B.A estimated score on repairs is a low risk and there may need to be a change.

Although there is still a level 2 where there is a need for improvement and risk, this result is at least better than the 
Journal of a Sustainable Global South, p-ISSN: 2579-6062

level of risk before improvements that reach level 5 are very high risk.

\section{CONCLUSION}

R.E.B.A method is very useful to determine musculoskeletal disorder risk of a postural work. Together with Computerized Added Design (CAD) software such as AutoCAD, postural work angle measure can be done faster and more precise. Also, CAD software function to simulate and design proposed tools and solutions.

Based on the results of the ergonomics evaluation, the assessment of the position of the operator's operating body from the heavy equipment manufacturer using the R.E.B.A method. The work station for installing an air cleaner based on R.E.B.A score calculation is 11 at level 4 with a very high level of risk in musculoskeletal, as a recommendation for improvement is to make a tool (a jig) in the installation

process, which is then reassessed, R.E.B.A score 3 is obtained, which indicates a low-risk level, or decreases by around $67 \%$ from the initial risk.

\section{REFERENCES}

[1] Corlett, E.N., \& Clark, T.S., "The Ergonomics of Workspaces and Machines: a Design Manual", USA: CRC Press, 2013.

[2] [2] NIOSH., "Musculoskeletal disorders and workplace factors, NIOSH Technical Report No. 97-141”, US Department of Health and Human Services, Cincinnati: National Institute for Occupational Safety and Health (NIOSH), 1997.

[3] [3] McAtamney, L.Y.N.N., \& Hignett, S., "REBA: Rapid Entire Body Assessment.", Applied ergonomics, 2000.

[4] [4] Yusof, N., Yusof, R., Basri, F., \& Soin, N., "Ergonomic evaluation of postural assessment among "canting" batik workers.", Advanced Engineering Forum, 2013.

[5] [5] Javidi, M., \& Naderi, M., (2014). "Analyzing dentists' body movement during work using two methods of REBA and OWAS. In International Conference on Advances in Biotechnology (BioTech). Proceedings", Global Science and Technology Forum, 2014.

[6] [6] Escobar, C.P., Dorris, N.T., Thomas, R., Maghsoodloo, S., \& Davis, J., "Critical Variables in the Application of Subjective Posture-Based Ergonomic Assessment Tools. IIE Annual Conference. Proceedings", Institute of Industrial and Systems Engineers (IISE), 2006.

[7] [7] Hunter, S.L., "Ergonomic evaluation of manufacturing system designs", Journal of Manufacturing Systems, 2002.

[8] [8] Bridger, R.S., "Introduction to Ergonomics", USA: CRC Press, 2008. 